\title{
AS THE WORM TURNS
}

GORDON J. SMITH, 588 Chalmers Avenue, Winnipeg, Manitoba R2L 0G6

In 1971 a milkweed began growing in our backyard. The first year it appeared I pulled it up not realizing what it was until the milky sap oozed from the broken stem. At the time I thought it was destroyed completely for it did not appear again. However, in May the following year, milkweed shoots began showing above ground and since then we have watched their growth, producing handsome flower clusters, occasional seed pods, and food for Monarch butterfly larvae.

Last year a Monarch butterfly was first noted depositing eggs on May 27. A total of 24 eggs were counted on three milkweed shoots $4-8 \mathrm{~cm}$. high coming up over a metre away from the main plant which was $65 \mathrm{~cm}$. in height. Only seven eggs were counted on the latter, most of them placed on the underside of the leaves. Practically all eggs deposited on stems disappeared in two or three days.

The first larva, about two mm long, was seen on June 3 and on June 25 pupae and caterpillars hanging upside down ready to transform were found under the leaves of the milkweed. Monarch butterflies were still laying eggs on the plant while the leaves were being devoured at an ever increasing rate by the growing larvae. One caterpillar was found hanging on the garage siding on June 28 and became a chrysalis the following day. Despite attempts to protect it, on July 14 it disappeared, a Common Grackle being suspected, (my wife having seen two nearby).

By mid-july the milkweed had lost all the upper leaves to the larvae as well as three undeveloped seed pods. On July 16 over 50 caterpillars were counted in the morning and by late afternoon the plant had been stripped bare of leaves. Most of the caterpillars disappeared, the few remaining ones feeding on scraps of leaves on the ground or the odd newly emerged milkweed sprout.

On July 20 another larva was seen on the garage siding, and, with better protection, a Monarch butterfly successfully emerged on August 8. A Common Grackle was seen in the backyard with a Monarch pupa on July 21, and, while we watched, broke it open and ate the contents, confirming our suspicion that this species was the culprit in the disappearance of some pupae at least.

Few larvae were seen in late July but pupae were hanging from our backyard fence and neighbor's garage, while others were found in the vegetable plot on cabbage and sunflower leaves. About two dozen pupae were seen but no doubt the total was higher as we only spotted the more obvious ones or found them when picking garden produce. The more exposed were placed in a can and several butterflies emerged.

After being denuded by the larvae the milkweed stems were cut down to ground level. New shoots began to grow and by mid-August the plant had reached a height of $70 \mathrm{~cm}$, remaining there until cut down by frost. The past year was exceptional in that the plant was completely defoliated. Cenerally a few caterpillars are present and the loss of leaves is not too noticeable to a casual observer.

My family and several neighborhood children thoroughly enjoyed this spectacle of nature in action. 

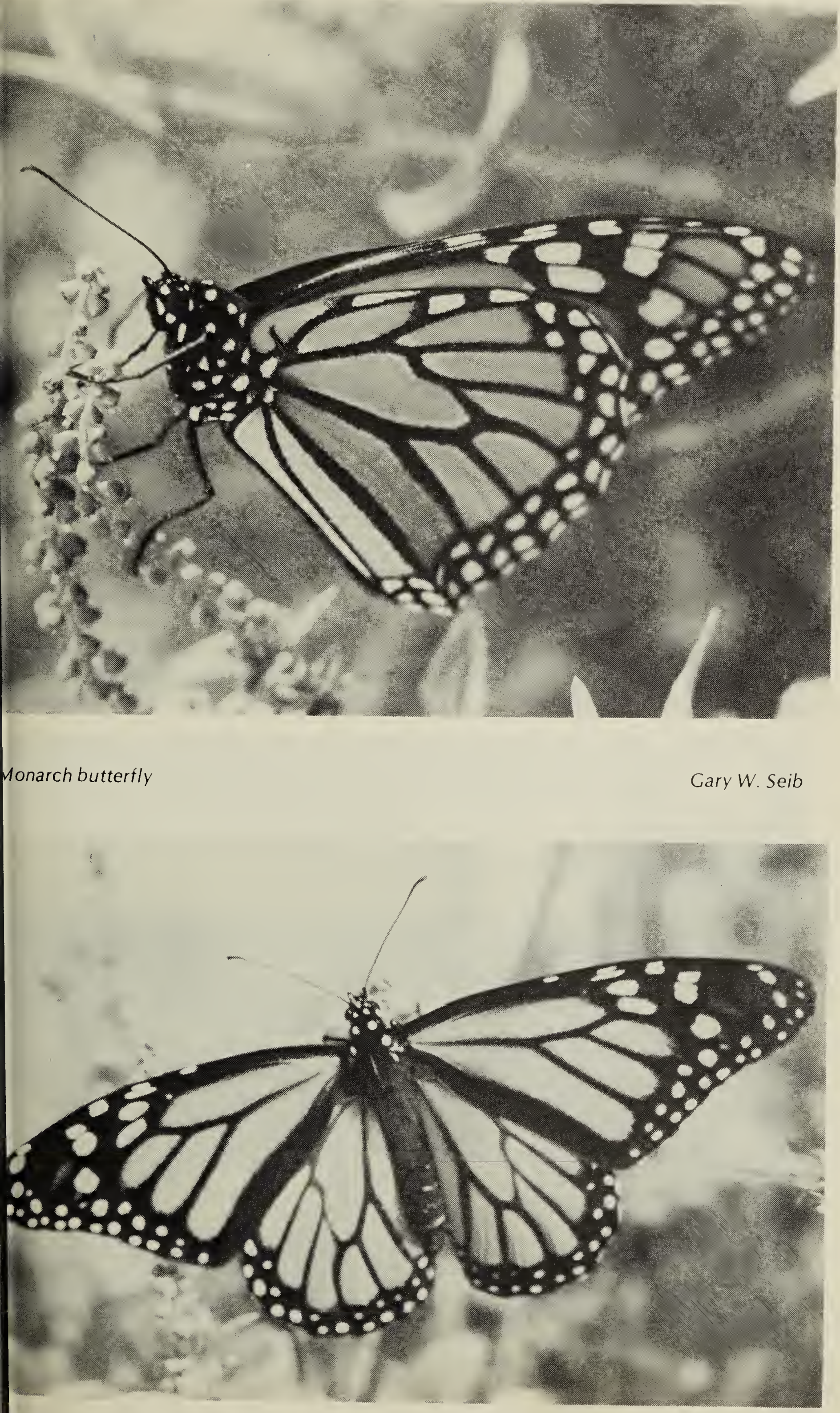